\title{
Gastro-oesophageal reflux - an important causative factor of severe tooth wear in Prader-Willi syndrome?
}

\author{
Ronnaug Saeves $^{1 *}$ (D), Finn Strøm², Leiv Sandvik ${ }^{3}$ and Hilde Nordgarden ${ }^{1}$
}

\begin{abstract}
Background: Prader-Willi syndrome (PWS) is the most common genetic human obesity syndrome and is characterized by hypotonia, endocrine disturbances, hyperphagia, obesity and mild mental retardation. Oral abnormalities, such as decreased salivary flow rates and extreme tooth wear, have also been described. Studies have shown a significant increase in reflux symptoms in individuals with obstuctive sleep apnoea syndrome and increased BMI, both of which are typical findings in PWS. Gastro-oesophageal reflux disease (GORD) has been identified in some individuals with PWS and is a significant intrinsic factor in dental tooth wear. The aim of this study was therefore to estimate the prevalence of GORD in adults and children and to evaluate a possible correlation between GORD and tooth wear in adults with PWS. They were all registered at the TAKO-centre.

Results: Twenty-nine individuals, 17 adults with a mean age of 32.6 years (range 18-48) and 12 children with a mean age of 8.8 years (range 3-17), agreed to undergo 24-hour oesophageal pH monitoring, and $90 \%$ of those enrolled managed to complete the examination. Four children and eleven adults were diagnosed with pathological gastro-oesophageal reflux, which is defined as acid exposure (pH less than 4) more than 3.6 or 4.3 percent of the time, respectively. Manometry performed in the adult group showed a pathologically high lower oesophageal sphincter pressure in four of the five individuals who had normal oesophageal $\mathrm{pH}$ values (pH under 4 less than $4.3 \%$ of the time). The two groups (reflux and non-reflux) were well balanced according to BMl, genotype, tooth grinding and hyposalivation. However, twice as many individuals in the reflux group as in the non-reflux group reported high consumption of acidic foods and drinks. Increased tooth wear was significantly correlated with GORD in the two groups (reflux $n=6$ and non-reflux $n=6$ ).

Conclusions: The prevalence of gastro-oesophageal reflux is high in individuals with PWS. Tooth wear was strongly associated with GORD and acidic drinks, and both may be important aetiological factors underlying the extreme tooth wear in this group. Our data suggest a need for routine screening for GORD and dental wear in young individuals with Prader-Willi syndrome.
\end{abstract}

Keywords: GORD, tooth wear, Prader-Willi syndrome

\section{Background}

Prader-Willi syndrome (PWS) is a disorder affecting multiple organ systems and is the most common genetic human obesity syndrome. Epidemiological surveys estimate that its population prevalence reaches 1:52000 [1-3], and the gender ratio is close to $1 / 1[1,4]$. The genetic mechanisms resulting in PWS are complex. The majority of individuals with PWS (70\%) have a paternally derived

\footnotetext{
*Correspondence: ronnaug.saeves@tako.no

${ }^{1}$ TAKO-centre, Lovisenberg Diaconal Hospital, Pb 4970 Nydalen, 0440 Oslo,

Norway

Full list of author information is available at the end of the article
}

deletion of 15q11-13, while maternal disomy 15 (UPD) occurs in $25 \%$ of individuals with PWS, and the remaining 2 to $5 \%$ have imprinting defects $[5,6]$. The typical PWS deletion falls into one of two classes, type 1 or type 2, depending on the size and the chromosome breakpoint position. When the genotype-phenotype relationships become clearer, it may be clinically important to subtype the deletion classes [7]. Clinical diagnostic criteria have been developed, but as clinically overlapping disorders exist, the diagnosis must be confirmed by genetic testing [8].

PWS has a characteristic phenotype that includes severe neonatal hypotonia, early feeding problems, childhood 
onset hyperphagia, obesity, short stature associated with growth hormone deficiency, a high pain threshold and intellectual disability [9-11]. The syndrome has traditionally been described as having two nutritional stages: poor feeding and failure to thrive in infancy followed by hyperphagia leading to obesity in later childhood [11-13]. The aetiology of the switch from poor feeding to hyperphagia is thought to be associated with abnormalities in the hypothalamic circuitry [12]. The obesity can be controlled by strict dietary restrictions. Growth hormone treatment improves growth, physical phenotype and body composition [8]. The Necdin gene is important for the differentiation of central and peripheral sensory neurons and is congenitally absent in PWS [14]. A narrow forehead, almond-shaped eyes, down-turned corners of the mouth and a thin upper lip are characteristic facial features of PWS. Varying degrees of oral motor dysfunction are also common in affected individuals [15].

Thick, viscous saliva is a consistent finding in individuals with PWS [16-19]. Decreased salivary flow rates and increased amounts of salivary ions and proteins have also been reported $[16,17,20]$ as well as severe tooth wear $[18$, $21,22]$. Tooth wear may result from attrition, abrasion, erosion or a combination of these factors. Attrition refers to the loss of enamel and dentin caused by the action of antagonistic teeth, while abrasion refers to the loss of tooth structure caused by other forms of physical wear due to mechanical processes involving foreign substances or objects. Erosion refers to chemical wear due to extrinsic or intrinsic acids $[23,24]$. The microscopic structure of enamel and dentin has been found to be normal in teeth from individuals with PWS [25]. There are many causes of tooth wear, and it thus may be difficult to identify the aetiology in individual cases. However, the pattern of tooth wear in individuals with PWS suggests that erosive tooth wear is an important factor [22].

Gastro-oesophageal reflux disease (GORD) is an aspect of general health that may affect erosive tooth wear, and it has been described in one case report [26]. GORD is a significant intrinsic factor in erosive tooth wear [27-31]. Excessive daytime sleepiness, sleep apnoea and central obesity are common in individuals with PWS [32-34]. Studies have shown a significant increase in reflux symptoms in individuals with confirmed obstructive sleep apnoea syndrome and increased BMI (Body Mass Index) $[35,36]$. Central adiposity may be the most important risk factor for the development of reflux [37]. To our knowledge no studies of gastro-oesophageal reflux in PWS have been published. Due to the extreme tooth wear in many individuals with PWS, GORD may be a serious problem and a causal factor in tooth wear for many individuals in this group.
The aim of this study was to explore the prevalence of pathological GORD in adults and children and to evaluate a possible correlation between GORD and tooth wear in adults with Prader-Willi syndrome. The null hypothesis was no difference in the prevalence of tooth wear between individuals with and without pathological gastro-oesophageal reflux.

\section{Methods}

This study was performed at the TAKO-centre, a national resource centre for oral health in rare medical conditions (frequency fewer than 1:10 000), Lovisenberg Diaconal Hospital (LDH), Oslo, Norway. The study followed an observational cross-sectional study design.

The study protocol was approved by the Regional Committee for Medical Research Ethics and informed consent was obtained from all participants. For juvenile participants under 18 years of age and adult participants with guardians, informed consent was also obtained from a parent or guardian.

\section{Study participants}

Fifty individuals, all of whom had been included in previous studies identifying salivary flow and tooth wear $[19,22]$, were invited to participate in the present study. They received written information, designed for both children and adults, describing the study. Eighteen adults responded and agreed to participate. One man who initially agreed to participate later changed his mind. Five children responded and agreed to participate. In addition, seven more children were included. All had been examined and followed at the TAKO-centre during the past three years, and the same data were available for them as for those included in previous studies. The final study group comprised 17 adults $(11 \mathrm{~F}, 6 \mathrm{M}$, mean age $=32.6$ years; range $18-48)$ and 12 children $(6 \mathrm{~F}, 6 \mathrm{M}$, mean age $=8.8$ years; range $3-17$ ) .

\section{Twenty-four-hour oesophageal pH monitoring}

Seven adults were subjected to manometry and 24-hour oesophageal $\mathrm{pH}$ monitoring at Lovisenberg Diaconal Hospital, and six of them managed to complete the examinations, while ten individuals were evaluated at other local hospitals. Prior to and after each examination, the $\mathrm{pH}$ electrodes were calibrated using standard methods. Oesophageal manometry was performed in order to define the position of the sensor, $5 \mathrm{~cm}$ above the lower oesophageal sphincter (LOS), and the pressure of the LOS. Continuous $\mathrm{pH}$ recording was performed for 24 hours, and the total reflux time during the day and night was registered. The limits for pathological gastro-oesophageal reflux with acid exposure were set to a pH under 4 more than $4.3 \%$ of the time for adults [38] and $3.6 \%$ of the time for children [39]. 
Twelve children were referred to their local hospital to evaluate the degree of GORD. Ten of them underwent 24-hour oesophageal $\mathrm{pH}$ monitoring conducted at seven different hospitals throughout the country. None of the 29 participants had undergone any prior surgical treatment for GORD (i.e., open Nissen fundoplication), and none had been treated with percutaneous endoscopic gastrostomy (PEG).

\section{Clinical assessments}

Children: BMI criteria for the age group 3-17 years of age $(n=12)$ were age- and gender-adjusted by comparing their BMI with the age- and gender-specific cut-off values provided by the International Obesity Task Force (IOTF) [40]. Tooth wear was not evaluated in the younger age group (3-17 years) because many had mixed dentition. We also lacked baseline data from seven participants.

Adults: All adult study participants were examined once by the same examiner and underwent an anamnestic interview either during the consultation or, if parents or guardian did not attend the consultation, by telephone with a parent or guardian. The interview focused on oral and general health and nutrition, as well as symptoms of sleep disorders and gastric reflux. The frequency of consumption of acidic food and drinks was categorized as follows: more than once daily, once daily, several times per week, once per week, or never. Information about tooth grinding was also obtained.

BMI was calculated on the basis of measured height and weight. To define the BMI categories $\left(\mathrm{kg} / \mathrm{m}^{2}\right)$, the sample was divided into four groups (underweight $(<19.9))$, normal weight (20-24.9), overweight (25-29.9) and obese $(\geq 30))$.

Dental impressions (Aroma Fine Plus Normal Set, Alginate, GC Corporation, Tokyo, Japan) were collected for adult individuals. Tooth wear was evaluated using two indices, the Visual Erosion Dental Examination (VEDE) scoring system [41] and a modified individual tooth wear index $\left(\mathrm{I}_{\mathrm{A}}\right)$ [42]. The VEDE-index, a modification of the dental erosion index proposed by Lussi [43], is a 6-point scoring system that contains a visual guide with clinical photographs: $0=$ no erosive wear; $1=$ loss of enamel surface characteristics; 2 =loss of enamel surface contour; $3=$ loss of dentine from less than one-third of the surface; $4=$ loss of dentine from more than one-third and less than twothirds of the surface; $5=$ loss of dentine from more than two-thirds of the surface. An individual mean VEDE-score was calculated by summing up the surface score (labial/ palatinal) evaluated by clinical examination and on dental casts for each tooth from upper right canine to upper left canine divided by the number of teeth present.

Tooth wear on the occluding surfaces was evaluated on dental casts and intraoral photographs using the $\mathrm{I}_{\mathrm{A}}$ index. This index recorded tooth wear on a 4 -point scale: $0=$ no or minimal wear; $1=$ wear of enamel down to dentine spots; 2 =wear of the dentine down to one-third of the crown height; 3 =wear of the dentine greater than onethird of crown height. In this study, the presence of a dental prosthetic crown due to tooth wear (according to the dental records) also qualified as a score of 3. The individual tooth wear index $\left(\mathrm{I}_{\mathrm{A}}\right)$ was calculated using the following formula: $\left(10 G_{1}+30 G_{2}+100 G_{3}\right) /\left(G_{0}+G_{1}+G_{2}+G_{3}\right)$, where $G_{0}, G_{1}, G_{2}$ and $G_{3}=$ number of teeth with occlusal wear scores of $0,1,2$ and 3, respectively [42]. Tooth wear was first evaluated in all participants by four examiners in $2007 / 2008$, and the results from that evaluation were originally described in a previous paper [22] and serve as a baseline for this report. In 2016, tooth wear was evaluated by one examiner (RS). The scores by RS in 2007 were close to the mean of the four examiners. The differences between the scores $\left(\mathrm{I}_{\mathrm{A}}\right.$ and VEDE) from 2007 and 2016 were used in the data analyses.

\section{Statistical analysis}

When comparing tooth wear $\left(\mathrm{I}_{\mathrm{A}^{-}}\right.$and VEDE index) between the two groups (the pathological gastrooesophageal reflux and the non-pathological gastrooesophageal reflux groups) an independent-samples ttest was applied. This application was based on the assumption that these variables are normally distributed. By using the findings from a relevant simulation study [44], we found that this assumption was adequately met for both variables.

A significance level of $5 \%$ was used throughout this work. The statistical analysis was carried out using the statistical software program (SPSS@); v. 24.0, SPSS Inc., Chicago, III., USA).

\section{Results}

Anamnestic and medical information about the study group $(n=29)$ is shown in Table 1 . Three adults in the present study reported dysphagia and regurgitation. Four children and eleven adults were diagnosed with pathological gastro-oesophageal reflux with acid exposure $(\mathrm{pH}$ less than 4) more than 3.6 and 4.3 percent of the time, respectively (Table 2 ).

Two children did not complete the 24-hour oesophageal $\mathrm{pH}$ monitoring, but medication was initiated based on clinical signs.

The oesophageal position of the $\mathrm{pH}$ sensor, $5 \mathrm{~cm}$ above the lower oesophageal sphincter (LOS), was monitored. A pathologically high lower oesophageal sphincter pressure was reported in three of five individuals who had normal oesophageal $\mathrm{pH}$ values (a $\mathrm{pH}$ under 4 less than $4.3 \%$ of the time).

Data from the manometry and 24-hour oesophageal $\mathrm{pH}$ monitoring as well as the BMI, genotype, tooth grinding, intake of acidic foods and drinks and unstimulated 
Table 1 Characteristics of the study population $n=29$

\begin{tabular}{|c|c|c|c|}
\hline & $\begin{array}{l}\text { Age 3-17 yr } \\
n\end{array}$ & $\begin{array}{l}\text { Age } 18-48 \text { yr } \\
\mathrm{n}\end{array}$ & Total, n (\%) \\
\hline \multicolumn{4}{|l|}{ Sex } \\
\hline Female & 6 & 11 & 17 (59 \%) \\
\hline Male & 6 & 6 & 12 (41\%) \\
\hline \multicolumn{4}{|l|}{ Genetic mechanisms } \\
\hline Del15 & 7 & 12 & $19(66 \%)$ \\
\hline UPD15 & 5 & 5 & $10(35 \%)$ \\
\hline \multicolumn{4}{|l|}{ Body mass index (BMI) } \\
\hline Underweight (<19.9) & 1 & 0 & $1(4 \%)$ \\
\hline Normal weight (20-24.9) & 8 & 4 & $12(41 \%)$ \\
\hline Overweight (25-29.9) & 1 & 5 & $6(21 \%)$ \\
\hline Obese $(\geq 30)$ & 2 & 7 & $9(31 \%)$ \\
\hline \multicolumn{4}{|l|}{ Sleep disorder } \\
\hline Snoring & 3 & 7 & $10(35 \%)$ \\
\hline Enlarged adenoids & 3 & 6 & $9(31 \%)$ \\
\hline Apnoea /CPAP & 3 & 6 & 9 (31\%) \\
\hline
\end{tabular}

Del15, deletion of the paternal chromosome 15q11-q13; UPD15, maternal uniparental disomy for chromosome 15; BMI was age- and sex adjusted for individuals 3-17 years according to the International Obesity Task Force (IONT) standards [40]. Sleep disorders were assessed by an ENT specialist

whole saliva secretion for the 16 adults are presented in Table 3. One adult failed to complete the 24-hour oesophageal $\mathrm{pH}$ monitoring. Three individuals in the nonreflux group were evaluated and had been diagnosed with pathological reflux in 2007; they used reflux medication during the whole tooth wear registration period. The two groups (the reflux and non-reflux groups) were well balanced with respect to the following variables: BMI, genotype, tooth grinding and hyposalivation. However, twice as many individuals in the reflux group as in the non-reflux group reported high levels of consumption of acidic foods and drinks. The mean age was 26.8 years in the reflux group and 35.5 years in the non-reflux group.

Increases in tooth wear as the mean $\mathrm{I}_{\mathrm{A}}$ and VEDE scores in the two groups (reflux $n=6$ and non-reflux $n=6$ ) registered over a mean of 7.5 years $(3-9,5)$ are presented in Table 4 . The increase in tooth wear was significantly correlated with GORD. Four individuals were excluded from the data analysis, two due to pathologically high LOS

Table 2 Gastro-oesophageal reflux in the study population $n=29$

Age 3-17 yr Age 18-48 yr Total, $n(\%)$

n $n$

\begin{tabular}{llll}
\hline Gastro-oesophageal reflux & & \\
Pathological & 4 & 11 & $15(52 \%)$ \\
Non pathological & 6 & 5 & $11(38 \%)$ \\
Reflux (clinical) & 2 & & $2(7 \%)$ \\
N/a & & 1 & $1(4 \%)$ \\
\hline
\end{tabular}

pressure $(>90 \mathrm{mmHg})$ and two because they had dental crowns placed on all their teeth following the first tooth wear registration in 2007. Three individuals were diagnosed with GORD diagnosis and used proton pump inhibitors for the whole period of tooth wear registration; these individuals were placed in the non-reflux group.

\section{Discussion}

As far as we know, this study is the first to investigate the prevalence of gastro-oesophageal reflux disease (GORD) using 24-hour oesophageal $\mathrm{pH}$ monitoring and to evaluate the association of GORD with tooth wear in a group of individuals with Prader-Willi syndrome. Fiftytwo percent of the total study group (17 adults, 12 children) and 69 percent of the adults showed pathological gastro-oesophageal reflux. This study demonstrated a statistically significant association between GORD and tooth wear in the adult study group. The null hypothesis was therefore rejected.

The study group was small, and a larger group would have thus strengthened the results. However, PWS is a rare disorder, and as many as 17 of 26 adults who participated in the previous study in 2007 responded. Good cooperation was necessary to participate in the evaluation of 24-hour oesophageal $\mathrm{pH}$ monitoring, and when invited, several parents and guardians reported that it would be too challenging to participate in this study. The participants came from all over Norway, and for this reason, the 24-hour oesophageal $\mathrm{pH}$ monitoring needed to be completed at twelve different hospitals. Possible differences in the procedures may entail bias. Three individuals in the non-reflux group were evaluated and had been diagnosed with pathological reflux in 2007; they used reflux medication during the whole tooth wear registration period. Minor leakage to the oesophagus in this periode thus cannot be excluded.

The individuals were referred for their evaluation of their 24-hour oesophageal acid exposure, and data on the manometry findings were not always noted in the medical reports sent to us. However, pathologically increased lower oesophageal sphincter (LOS) pressure was reported in five of 16 individuals. Data on LOS was missing in five individuals, and those data would have strengthened the results.

All study participants were examined once by a single examiner (RS) and tooth wear was evaluated based on two indices using dental casts. In the previous study, four calibrated and blinded examiners evaluated tooth wear, based on the VEDE- and IA indices to counter potential bias. It was not possible to utilize four examiners during the last examination. However, the principal examiner (RS) was an average observer of the four, which indicates acceptable validity. 
Table 3 Twenty-four-hour oesophageal acid exposure and manometry findings in 16 adults

\begin{tabular}{|c|c|c|c|c|c|c|c|c|c|c|}
\hline Individual & $\begin{array}{l}\text { Age } \\
\text { (yr) }\end{array}$ & Sex & Genotype & $\mathrm{BMI}$ & $\begin{array}{l}\text { Reflux } \% \\
\text { Pat }>4,3 \%{ }^{\text {a }}\end{array}$ & $\begin{array}{l}\text { LOS pressure } \\
(\mathrm{mmHg})^{b}\end{array}$ & $\begin{array}{l}\text { Relaxation } \\
\text { pressure } \\
(\mathrm{mmHg})^{c}\end{array}$ & $\begin{array}{l}\text { UHS } \\
\mathrm{mL} / \mathrm{min}^{\mathrm{d}}\end{array}$ & $\begin{array}{l}\text { Tooth } \\
\text { grinding }\end{array}$ & $\begin{array}{l}\text { Acidic foods } \\
\text { and drinks }\end{array}$ \\
\hline 1 & 38 & $F$ & Del & 24,2 & 29 & 30 & Norm & 0.17 & no & 1 \\
\hline 2 & 26 & M & Del & 33,3 & 20 & N/a & $\mathrm{N} / \mathrm{a}$ & 0.09 & yes & 1 \\
\hline 3 & 20 & $\mathrm{~F}$ & UPD & 41,1 & 4,8 & N/a & $\mathrm{N} / \mathrm{a}$ & 0.05 & no & 1 \\
\hline 4 & 42 & M & Del & 38,1 & 0,2 & 100 & 39 & 0.08 & yes & 1 \\
\hline 5 & 41 & $\mathrm{~F}$ & Del & 44,7 & 2,4 & 89 & Norm & 0.02 & no & 1 \\
\hline 6 & 35 & $\mathrm{~F}$ & Del & 37,6 & 2,9 & 84.9 & Norm & 0.33 & no & 0 \\
\hline 7 & 25 & M & Del & 34,9 & 18 & Norm & Norm & 0.09 & no & 1 \\
\hline 8 & 18 & $\mathrm{~F}$ & Del & 27,6 & 6,9 & N/a & N/a & 0.04 & yes & 0 \\
\hline 9 & 32 & M & UPD & 25,1 & 13,8 & Norm & Norm & 0.05 & yes & 1 \\
\hline 10 & 40 & $\mathrm{~F}$ & UPD & 23,0 & 0,8 & 91 & Norm & 0.24 & yes & 1 \\
\hline 11 & 25 & $\mathrm{~F}$ & Del & 26,4 & 9,6 & 16 & Norm & 0.16 & yes & 1 \\
\hline 12 & 33 & $\mathrm{~F}$ & Del & 22,5 & 0,3 & N/a & N/a & 0.06 & no & 0 \\
\hline 13 & 34 & M & Del & 26,8 & 10,9 & 7.6 & Norm & 0.11 & no & 1 \\
\hline 14 & 31 & $\mathrm{~F}$ & Del & 31,0 & 27,1 & 44 & 29 & 0.2 & yes & 1 \\
\hline 15 & 48 & M & UPD & 29 & 6 & 31 & 25.6 & 0.27 & yes & 1 \\
\hline 16 & 31 & $\mathrm{~F}$ & Del & 24,4 & 6,7 & N/a & $\mathrm{N} / \mathrm{a}$ & 0.21 & no & 1 \\
\hline
\end{tabular}

${ }^{a}$ Reflux (pathological > 4.3\%)

b Lower Oesophageal Sphincter pressure (normal values: $13-43 \mathrm{mmHg}$ )

'Relaxation pressure (normal value $<15$ )

dUnstimulated whole saliva (hyposalivation $\leq 0.10 \mathrm{~mL} / \mathrm{min}$ )

${ }^{\mathrm{e}}$ Acidic foods and drinks (sugared and diet soft drinks carbonated/not carbonated) more than once daily

In this study, we were able to follow the development and increase in tooth wear for a mean of 7.5 years $(3.0-$ 9.5) for all adult participants. Moderate tooth wear may progress as a part of normal aging [45]. In the present study, the mean age of the reflux group was 27 years, and in the non-reflux group, it was 36 years. After adjustments for age and age-related physiological tooth wear, the difference in tooth wear between the two groups would have been even greater.

Gastro-oesophageal reflux is an aspect of general health that can affect erosive tooth wear [28-31]. Both the acid and fat contents of food are known to trigger GORD. In the present study, looking primarily at erosive tooth wear, we focused in particular on the content of acid and not fat in the diet. Individuals with PWS live on a strict diet $(1100-1200 \mathrm{kcal})$ and eat regularely. Their diet is based on vegetables and light products, and the focus is on reducing the fat content of their food. We therefore, do not think that fat is a trigger for GORD in the participants. Focusing

Table 4 Tooth wear in the adult study population presented as mean $I_{A}$ and mean VEDE

\begin{tabular}{llll}
\hline Indices & $\begin{array}{l}\text { Pathological } \\
\text { reflux } n=6\end{array}$ & $\begin{array}{l}\text { Non-pathological } \\
\text { reflux } n=6\end{array}$ & $p$-value \\
\hline$I_{\text {A }}$ & $14.63 \pm 9.58$ & $2.81 \pm 2.42$ & 0.028 \\
VEDE & $0.65 \pm 0.33$ & $0.16 \pm 0.14$ & 0.013 \\
\hline
\end{tabular}

Statistical significance $(p<0.05)$ on the aetiology of tooth wear, all aspects of aetiology and consequences were not included in the study design. Studies have shown a significant increase in GORD symptoms in individuals with obstructive sleep apnoea syndrome, as well as increased BMI and central adiposity [36, 37] all of which are frequent risk factors and common to PWS [32]. The typical symptoms of GORD are heartburn and acid regurgitation. More atypical GORD symptoms may include a chronic cough, hoarseness, sleep disturbances and chest pains [46]. The prevalence of GORD varies in different parts of the world. The highest population prevalence has been reported in Europe (12-24\%) [47, 48]. In a recently published Norwegian study [48], the prevalence of at least weekly GORD was found to be $17.1 \%$, and that of severe GORD of $6.7 \%$ reported due to GORD symptoms. In our small group study, 11 of $16(69 \%)$ adults underwent GORD diagnosis. Four out of five individuals in the non-reflux group presented with high lower oesophageal sphincter pressure $>80 \mathrm{mmHg}$ (normal range: $13-43 \mathrm{mmHg}$ ). The high LOS pressure may explain the minor leakage of acid to the oesophagus in these individuals. This condition can occur at any age, from early childhood to the ninth decade of life. The two participants who had LOS pressure of 90 and $100 \mathrm{mmHg}$ (non-reflux) had received dental crowns on all their teeth due to extreme tooth wear after the first examination in 2007. For this reason, GORD at an earlier age cannot be excluded as an 
aetiological factor. None of the PWS study participants reported symptoms of reflux or heartburn in the anamnestic interview in 2007. The symptoms of GORD may have been underreported, possibly due to the high pain threshold of PWS, which could in turn lead to the decreased recognition of injury or illness [49]. Alternatively, individuals with the disorder may regard their long-standing reflux symptoms as "normal" and therefore not noteworthy. After starting on proton pump inhibitor medication, some of the participants reported GORD symptoms if the medication for some reason was stopped for a period. Three individuals in the present study reported dysphagia and regurgitation. This is in line with the findings of a study from 1987. Rumination is characterized by repetitive regurgitation of gastric contents into the oropharynx [50] and was reported by Alexander [51] in 53 out of 313 (17\%) assessed individuals with PWS. No data have been published on rumination in PWS since 1987.

Tooth wear may be caused by attrition, erosion, abrasion or a combination of these processes. In the present study, two indices were used, one to focus on erosive tooth wear (VEDE) and one designed to measure abrasion or attrition on occluding surfaces $\left(\mathrm{I}_{\mathrm{A}}\right)$. Extensive tooth wear in PWS has been demonstrated and appears to be a significant problem $[18,22]$. The multifactorial nature of tooth wear, influenced by variables such as hyposalivation, tooth grinding, and intrinsic (gastric) and extrinsic acids (most commonly dietary), makes it difficult to establish its aetiology. GORD is a significant intrinsic factor in erosive tooth wear $[29,30]$ and is consistent with our obsevation of a strong association between GORD and tooth wear. The microscopic structure of enamel and dentin in teeth from individuals with PWS has been found to be normal. The enamel surface was generally smooth without structure, but could in some aspects resemble the effects of an acidic agent [25].

Earlier studies found that saliva protects the teeth against tooth wear [21, 52]. In our previous study, the low salivary flow rate did not maintain a significant association with tooth wear and is therefore possibly only a minor contributory factor in extreme tooth wear. In the present study, hyposalivation was well balanced in both the reflux and non-reflux groups. Dietary acids are considered to be the most common cause of erosive tooth wear by many researchers $[30,53,54]$. These results are in accordance with the findings of the present study.

\section{Conclusion}

To our knowledge, this is the first study addressing GORD in Prader-Willi syndrome. The prevalence of GORD seems to be high and to increase with age in PWS. Tooth wear was strongly associated with GORD and the intake of acidic drinks, and both may be important aetiological factors for the extreme tooth wear observed in this group. It is important to be aware that GORD may be a health challenge in individuals with PWS, and more studies on this are clearly necessary. Our data suggest a need for routine screening for GORD and tooth wear in young individuals with Prader-Willi syndrome.

\section{Abbreviations}

BMI: Body mass index; GORD: Gastro-oesophageal reflux disease;

$\mathrm{I}_{\mathrm{A}}$ : Individual tooth wear index; LOS: Lower oesophageal sphincter;

PWS: Prader-Willi syndrome; VEDE: Visual erosion dental examination

\section{Acknowledgements}

The authors thank the Norwegian Prader-Willi syndrome association as well as all participants and their families.

\section{Availability of data and materials}

The datasets used and analysed in this study are available from the corresponding author upon reasonable request.

\section{Authors' contributions}

RS developed the study design and established the primary aims in cooperation with HN. RS and FS were responsible for the data collection and analyses. RS wrote the paper in consultation with the co-authors and takes the responsibility for the content. LS supported RS with the statistical analysis section in the paper. HN critically reviewed the paper and approved the final version. All authors read and approved the final manuscript.

\section{Authors' information}

RS; DDS, PhD. FS; Cand Med, Specialist in Gastroenerology. LS; Professor, Biostatistics. HN; DDS, PhD. Head of the TAKO-centre.

Ethics approval and consent to participate

The study protocol was approved by the Regional Committee for Medical Research Ethics, South-East Norway. Ref nr; 2013/1021.

\section{Consent for publication}

Informed consent was obtained from all participants. When participants were under 18 years of age or had a legal guardian, informed consent was obtained from the parent or guardian as appropriate.

\section{Competing interests}

The authors declare that they have no competing interests.

\section{Publisher's Note}

Springer Nature remains neutral with regard to jurisdictional claims in published maps and institutional affiliations.

\section{Author details}

'TAKO-centre, Lovisenberg Diaconal Hospital, Pb 4970 Nydalen, 0440 Oslo, Norway. ${ }^{2}$ Lovisenberg Diaconal Hospital, Oslo, Norway. ${ }^{3}$ Department of Biostatistics and Epidemiology, Oslo University Hospital, Oslo, Norway.

Received: 31 August 2017 Accepted: 16 April 2018

Published online: 23 April 2018

\section{References}

1. Whittington JE, Holland AJ, Webb T, Butler J, Clarke D, Boer H. Population prevalence and estimated birth incidence and mortality rate for people with Prader-Willi syndrome in one UK Health Region. J Med Genet. 2001;38:792-8.

2. Smith A, Egan J, Ridley G, Haan E, Montgomery P, Williams K, et al. Birth prevalence of Prader-Willi syndrome in Australia. Arch Dis Child. 2003;88:263-4.

3. Vogels A, Van Den Ende J, Keymolen K, Mortier G, Devriendt K, Legius E, et al. Minimum prevalence, birth incidence and cause of death for Prader-Willi syndrome in Flanders. Eur J Hum Genet. 2004;12:238-40.

4. Akefeldt A, Gillberg C, Larsson C. Prader-Willi syndrome in a Swedish rural county: epidemiological aspects. Dev Med Child Neurol. 1991;33:715-21.

5. Driscoll DJ, Waters MF, Williams CA, Zori RT, Glenn CC, Avidano KM, et al. A DNA methylation imprint, determined by the sex of the parent, distinguishes the Angelman and Prader-Willi syndromes. Genomics. 1992;13:917-24. 
6. Cassidy SB, Forsythe M, Heeger S, Nicholls RD, Schork N, Benn P, et al. Comparison of phenotype between patients with Prader-Willi syndrome due to deletion 15q and uniparental disomy 15. Am J Med Genet. 1997;68:433-40.

7. Kim SJ, Miller UL, Kuipers PJ, German JR, Beaudet AL, Sahoo T et al.: Unique and atypical deletions in Prader-Willi syndrome reveal distinct phenotypes. Eur J Hum Genet. 2012; 20:283-90.

8. Cassidy SB, Driscoll DJ. Prader-Willi syndrome. Eur J Hum Genet. 2009;17:3-13

9. Prader A. LAWH: Ein syndrom von adipositas, Kleinwuchs, Kryptorchismus, und Oligophrenie nach myotonieartigem Zustand in Neugeborenenalter. Schweiz Med Wochenschr. 1956;86:1260-1. Schweiz Med Wochenschr.

10. Holm VA, Cassidy SB, Butler MG, Hanchett JM, Greenswag LR, Whitman BY, et al. Prader-Willi syndrome: consensus diagnostic criteria. Pediatrics. 1993;91:398-402.

11. Gunay-Aygun M, Schwartz S, Heeger S, O'Riordan MA, Cassidy SB. The changing purpose of Prader-Willi syndrome clinical diagnostic criteria and proposed revised criteria. Pediatrics. 2001;108:E92.

12. Goldstone AP. Prader-Willi syndrome: advances in genetics, pathophysiology and treatment. Trends Endocrinol Metab. 2004;15:12-20.

13. Miller JL, Lynn CH, Driscoll DC, Goldstone AP, Gold JA, Kimonis V, et al. Nutritional phases in Prader-Willi syndrome. Am J Med Genet A. 2011;155:1040-9.

14. Jay $\mathrm{P}$, Rougeulle $\mathrm{C}$, Massacrier $\mathrm{A}$, Moncla A, Mattei MG, Malzac $\mathrm{P}$, et al. The human necdin gene, NDN, is maternally imprinted and located in the Prader-Willi syndrome chromosomal region. Nat Genet. 1997;17:357-61.

15. Saeves R, Asten P, Storhaug K, Bagesund M. Orofacial dysfunction in individuals with Prader-Willi syndrome assessed with NOT-S. Acta Odontol Scand. 2011;69:310-5.

16. Bray GA, Dahms WT, Swerdloff RS, Fiser RH, Atkinson RL, Carrel RE. The Prader-Willi syndrome: a study of 40 patients and a review of the literature. Medicine (Baltimore). 1983;62:59-80

17. Hart PS. Salivary abnormalities in Prader-Willi syndrome. Ann N Y Acad Sci. 1998;842:125-31.

18. Bailleul-Forestier I, Verhaeghe V, Fryns JP, Vinckier F, Declerck D, Vogels A. The oro-dental phenotype in Prader-Willi syndrome: a survey of 15 patients. Int J Paediatr Dent. 2008;18:40-7.

19. Saeves R, Nordgarden H, Storhaug K, Sandvik L, Espelid I. Salivary flow rate and oral findings in Prader-Willi syndrome: a case-control study. Int J Paediatr Dent. 2012;22:27-36.

20. Saeves R, Reseland JE, Kvam BM, Sandvik L, Nordgarden H. Saliva in Prader-Willi syndrome: quantitative and qualitative characteristics. Arch Oral Biol. 2012;57:1335-41.

21. Young W, Khan F, Brandt R, Savage N, Razek AA, Huang Q. Syndromes with salivary dysfunction predispose to tooth wear: Case reports of congenital dysfunction of major salivary glands, Prader-Willi, congenital rubella, and Sjogren's syndromes. Oral Surg Oral Med Oral Pathol Oral Radiol Endod. 2001;92:38-48.

22. Saeves R, Espelid I, Storhaug K, Sandvik L, Nordgarden H. Severe tooth wear in Prader-Willi syndrome. A case-control study. BMC Oral Health. 2012;12:12.

23. Ganss C, Young A, Lussi A. Tooth wear and erosion: Methodological issues in epidemiological and public health research and the future research agenda. Community Dental Health. 2011;28:191-5.

24. Lussi A, Ganss C: Erosive tooth wear. Monogr Oral Sci. Basel Krager. 2014;25:1-15.

25. Saeves R, Klinge RF, Risnes $S$. Microscopic structure of dental hard tissues in primary and permanent teeth from individuals with Prader-Willi syndrome. Arch Oral Biol. 2016;66:55-60

26. Bots $C P$, Schueler YT, Brand HS, van Nieuw AA. A patient with Prader-Willi syndrome. Characteristics, oral consequences and treatment options. Ned Tijdschr Tandheelkd. 2004;1 11:55-8.

27. Bartlett DW, Evans DF, Anggiansah A, Smith BG. A study of the association between gastro-oesophageal reflux and palatal dental erosion. Br Dent J. 1996;181:125-31.

28. Munoz JV, Herreros B, Sanchiz V, Amoros C, Hernandez V, Pascual I, et al. Dental and periodontal lesions in patients with gastro-oesophageal reflux disease. Dig Liver Dis. 2003;35:461-7.

29. Pace F, Pallotta S, Tonini M, Vakil N, Bianchi PG. Systematic review: gastrooesophageal reflux disease and dental lesions. Aliment Pharmacol Ther. 2008:27:1179-86

30. Holbrook WP, Furuholm J, Gudmundsson K, Theodors A, Meurman JH. Gastric reflux is a significant causative factor of tooth erosion. J Dent Res. 2009;88:422-6.

31. Wilder-Smith $\mathrm{CH}$, Materna A, Martig L, Lussi A. Longitudinal study of gastroesophageal reflux and erosive tooth wear. BMC Gastroenterol. 2017;17:113.

32. Butler JV, Whittington JE, Holland AJ, Boer H, Clarke D, Webb T. Prevalence of, and risk factors for, physical ill-health in people with Prader-Willi syndrome: a population-based study. Dev Med Child Neurol. 2002;44:248-55.
33. Yee BJ, Buchanan PR, Mahadev S, Banerjee D, Liu PY, Phillips C, et al. Assessment of sleep and breathing in adults with prader-willi syndrome: a case control series. J Clin Sleep Med. 2007;3:713-8.

34. Maas AP, Sinnema M, Didden R, Maaskant MA, Smits MG, SchranderStumpel $C$, et al. Sleep disturbances and behavioural problems in adults with Prader-Willi syndrome. J Intellect Disabil Res. 2010;54:906-17.

35. Valipour A, Makker HK, Hardy R, Emegbo S, Toma T, Spiro SG. Symptomatic gastroesophageal reflux in subjects with a breathing sleep disorder. Chest. 2002;121:1748-53.

36. Green BT, Broughton WA, O'Connor JB. Marked improvement in nocturnal gastroesophageal reflux in a large cohort of patients with obstructive sleep apnea treated with continuous positive airway pressure. Arch Intern Med. 2003;163:41-5.

37. Friedenberg FK, Xanthopoulos M, Foster GD, Richter JE. The association between gastroesophageal reflux disease and obesity. Am J Gastroenterol. 2008;103:2111-22.

38. Johnson LF, DeMeester TR. Twenty-four-hour pH monitoring of the distal esophagus. A quantitative measure of gastroesophageal reflux. Am J Gastroenterol. 1974;62:325-32.

39. Sondheimer JM, Haase GM. Simultaneous pH recordings from multiple esophageal sites in children with and without distal gastroesophageal reflux. J Pediatr Gastroenterol Nutr. 1988;7:46-51.

40. Cole TJ, Bellizzi MC, Flegal KM, Dietz WH. Establishing a standard definition for child overweight and obesity worldwide: international survey. BMJ. 2000; 320:1240-3.

41. Mulic A, Tveit AB, Wang NJ, Hove LH, Espelid I, Skaare AB. Reliability of two clinical scoring systems for dental erosive wear. Caries Res. 2010;44:294-9.

42. Ekfeldt A, Hugoson A, Bergendal T, Helkimo M. An individual tooth wear index and an analysis of factors correlated to incisal and occlusal wear in an adult Swedish population. Acta Odontol Scand. 1990;48:343-9.

43. Lussi A. Dental erosion clinical diagnosis and case history taking. Eur J Oral Sci. 1996;104:191-8.

44. Fagerland MW, Sandvik L. Performance of five two-sample location tests for skewed distributions with unequal variances. Contemp Clin Trials. 2009;30:490-6.

45. Van't Spijker A, Rodriguez JM, Kreulen CM, Bronkhorst EM, Bartlett DW, Creugers NH. Prevalence of tooth wear in adults. Int J Prosthodont. 2009;22:35-42.

46. Vakil N, van Zanten SV, Kahrilas P, Dent J, Jones R. The Montreal definition and classification of gastroesophageal reflux disease: a global, evidencebased consensus paper. Z Gastroenterol. 2007:45:1125-40.

47. Ronkainen J, Agreus L. Epidemiology of reflux symptoms and GORD. Best Pract Res Clin Gastroenterol. 2013;27:325-37.

48. Ness-Jensen E, Lindam A, Lagergren J, Hveem K. Changes in prevalence, incidence and spontaneous loss of gastro-oesophageal reflux symptoms: a prospective population-based cohort study, the HUNT study. Gut. 2012:61:1390-7.

49. Priano L, Miscio G, Grugni G, Milano E, Baudo S, Sellitti L, et al. On the origin of sensory impairment and altered pain perception in Prader-Willi syndrome: a neurophysiological study. Eur J Pain. 2009;13:829-35.

50. Olden KW. Rumination. Curr Treat Options Gastroenterol. 2001:4:351-8.

51. Alexander RC, Greenswag LR, Nowak AJ. Rumination and vomiting in Prader-Willi syndrome. Am J Med Genet. 1987;28:889-95.

52. Dawes C. Salivary flow patterns and the health of hard and soft oral tissues. J Am Dent Assoc. 2008;139(Suppl):18S-24S.

53. Dugmore CR, Rock WP. A multifactorial analysis of factors associated with dental erosion. Br Dent J. 2004;196:283-6.

54. Jensdottir T, Arnadottir IB, Thorsdottir I, Bardow A, Gudmundsson K Theodors A, et al. Relationship between dental erosion, soft drink consumption, and gastroesophageal reflux among Icelanders. Clin Oral Investig. 2004;8:91-6. 